\title{
Coopetition Balance and Coopetition Capability in Platform Ecosystems: Complementors' Perspective
}

\author{
Dong Kyoon Yoo \\ James Jungbae Roh \\ roh@rowan.edu \\ Sunyoung Cho \\ Ma Ga (Mark) Yang \\ dyoo@vsu.edu \\ Virginia State University Rowan University University of Texas, Rio Grande Valley West Chester University \\ sunyoung.cho@utrgv.edu \\ myang@wcupa.edu
}

\begin{abstract}
In a platform ecosystem, complementors can utilize various resources from a platform owner that receives a variety of products/services via complementors for better customers' choice and satisfaction. The literature has focused on the cooperative nature of the platform ecosystem. Less attention, however, has been given to coopetition (i.e., simultaneous strategic use of cooperation and competition). Drawing upon paradox theory, this study develops a research model that explains the individual and joint impact of coopetition balance and coopetition capability on relationship performance in a platform ecosystem. Based on survey data from 365 complementors to Amazon, this study illustrates that coopetition balance and coopetition capability have a significant impact on relationship performance. Additionally, coopetition capability moderates the relationship between coopetition balance and relationship performance. In particular, results show that coopetition capability is the most critical variable to enhance relationship performance. Theoretical and practical implications are discussed in this paper.
\end{abstract}

\section{Introduction}

Platform-based markets have been prevalent recently in various fields such as smartphones, video game consoles, search engines, or e-commerce [11, 30, 34]. As the effectiveness of the platform ecosystem relies on dynamic interactions among consumers, complementors, and a platform owner, their partnership has been emphasized [15, 21]. A large number of entrepreneurs, serving as complementors to a platform, have established their businesses by utilizing the technical, managerial, and logistical infrastructure of a platform.

This collaboration, however, has been polluted by a platform's entry into complementors' product markets. Studies have reported that complementors have been pushed out of their product space, not by competitors but by a platform owner [34]. As complementors depend heavily on having access to customers and resources through a platform, they are exposed to the risk of the asymmetric relationship. The literature finds that Amazon's direct competition with complementors results in reduced shipping cost, implying benefits for customers on the contrary to the welfare of complementors [34]. This emergence of competition in a platform ecosystem has certainly hindered small thirdparty sellers to grow in their businesses.

While direct competition with a platform owner would be adverse conditions, complementors should accept instead of ignoring coopetition and rather see a new opportunity by generating synergies over the paradoxical coexistence of cooperation and competition. Studies argue that competition seems to deteriorate cooperation at a given point in time, but the dynamic association between cooperation and competition will reinforce firms over time [15]. As firms need to oscillate between cooperation and competition, the purpose of this study is to examine the individual and joint impact of coopetition balance and coopetition capability, both of which mitigate negative tensions of coopetition, on relationship performance in the context of a platform ecosystem.

The present study contributes to providing insights into coopetition for academicians and practitioners. First, this study adds value to the body of the coopetition literature. Studies have focused on cooperative behaviors for value creation or examined competitive dynamics for superiority separately [20]. In other words, limited attention has been given to coopetition, simultaneous strategic use of cooperation and competition $[2,15]$. The literature accordingly calls for coopetition research, and this study provides an in-depth account of coopetition with a theory-driven research model and an empirical test.

Second, the present study contributes to enhancing understandings of coopetition with a contextual focus on a platform-based market. Researchers have emphasized cooperative dynamics in the platform business model [21]. Complementors, however, has less direct access to customers and more reliance on a platform's resources, indicating asymmetric relationships. Consequently, their capacity to cope with a wide spectrum of a platform's strategic positioning is 
critical. As the interplay of cooperation and competition would create or damage value cocreation, favorable conditions for complementors to facilitate positive performance should be investigated [15]. This study sheds light on offering a strategic guidance for complementors.

Third, the present study provides explanations to the literature by explicating how mixed results of coopetition can be reconciled. As firms seek to accomplish the best of cooperation and competition, there inevitably exists tensions between the two paradoxical coexistence. The two conflicting demands also result in differing outcomes: positive and negative [2]. It is important for firms to strike a right balance while pursing cooperation and competition simultaneously, but the current literature falls short of offering meaningful insights. In addition, coopetition capability is known to mitigate tensions arising from simultaneous cooperation and competition [1], but not many empirical studies are reported. This study examines coopetition balance and coopetition capability and investigates how their interactions escalate positive results from coopetition.

\section{Theoretical foundation: Paradoxical coexistence in coopetition}

The theory of paradox provides a theoretical foundation for coopetition. In the increasingly competitive, fast-paced environment, two conflicting demands are frequently requested to pursue jointly, often called as paradoxes, as part of adaptive capacity for survival and sustainability at the individual, team, and organizational levels: knowledge management (exploitation vs. exploration), strategy (cooperation vs. competition), organizational structure (centralization vs. decentralization), governance (relational vs. contractual), operations (quality excellence vs. innovation), teamwork (task- vs. relational oriented), employees life (work vs. home), and leadership (control vs. empowerment) [16]. Paradox is defined as "contradictory yet interrelated elements that exists simultaneously and persist over time" [29, p. 382]. As indicated, the concept entails the simultaneity and persistence of tensions between two competing goals [28], and complementors in the platform ecosystem are expected to manage ostensibly incompatible perspectives (i.e., cooperation and competition) for sustaining competitiveness. As paradoxes defy resolutions, scholars suggest three steps for manage it effectively, and those are insightful for complementors: (1) accepting, (2) accommodating, and (3) differentiating/integrating [28]. Accepting is related to "learning to live with the paradox" [17, p. 764]
Accommodating is associated with "defining a novel, creative synergy that addresses both oppositional elements together" [28, p. 1594]. Differentiating/integrating includes "honoring unique aspects of each notion" and combining them for synergies and linkages [28, p. 1594].

In the technical sense, a platform is defined as "an extensible technological foundation and the interfaces used by extensions that interoperate with it" [31, p. 267]. Also, platform ecosystems are describes as "a platform and its collection of complementary extensions" [31, p. 267]. This context can be well understood with the App store at Apple. However, we would like to focus more on an e-marketplace, "an Internet platform-based market through which both sides of an exchange buyers and sellers - conduct transactions" [18, p. 209]. In this platform environment, platform owners provide technical, managerial, and logistical infrastructure to complementors (i.e., third-party sellers) that in turn supply a variety of products to the platform.

Paradoxes carry illogical elements that generate uncertainty and ambiguity, and they enhance tensions cognitively or emotionally [28]. In the context of a platform ecosystem, complementors would be pressured with the entry into a product space by a platform owner. Tension is a double-edged sword that could generate innovative, optimistic behaviors, while significantly escalating needless stress, unnecessary frustration, and counterproductive defenses [22]. In other words, it can create a virtuous cycle that complementors identify new opportunities, integrate necessary resources, develop a new solution, and continue to sustain their competitive advantage. On the other hand, tension can fuel frustration, confusion, and defenses for complementors.

Two views have been reported when facing tensions: "dilemma" and "natural and persistent" [22]. The dilemma view sees tensions as tradeoffs, indicating that an organization/individual gives up one over the other with the idea of either/or. The "natural and persistent" view illustrates that firms are required to have ongoing responses rather than one-time resolution [28]. The "natural and persistent" view may appear as opportunities that escalate learning and adaptability [22, 28]. This study takes the view of "natural and persistent" as complementors should continually adjust their tensions with the proper relationship with a platform owner.

\section{What is coopetition?}

Given that a half of cooperation occurs among competitors, cooperation and competition are inseparably intertwined [3]. The two research streams, however, have evolved independently, and the literature has recently acknowledged the need for combining them 
simultaneously [15]. The literature defines coopetition as competing without killing the opposition and cooperating without ignoring self-interest [4]. Coopetition has been noticed in two different paths. Competition proceeds cooperation or vice versa [15]. At times, firms find themselves in working with their competitors with the pooling of increased complementarity of resources and synergetic combinations of market- or industry-specific expertise. They build trust with long-time rivals to mitigate price competition for general economic welfare and expand new markets and novel technologies by sharing risks. Coopetition, on the other hand, has been established from cooperation to competition. Firms pursue a coopetition strategy, especially when they need (1) technical capabilities, (2) share knowledge and resources, work together for events, technical standards, regulations, and (3) create oneness or we-ness, (4) create/expand new markets, and (5) collude on price [4, 20]. When the market matures, organizations see cooperation as inefficient strategy and move toward competition for financial optimization [20].

A stream of the coopetition study has flowed into illuminating its antecedents and consequences, although it is quite overlapped with separate studies on cooperation and competition. Antecedents to coopetition include risk reduction, cost sharing, and resource access and pooling $[3,15]$. Additionally, the literature presents consequences of coopetition such as better performance, incremental/radical innovations, and the diversity of technology $[3,15,26]$.

Another focus on coopetition is its impact on value creation or value appropriation [13]. Studies have elaborated on outcomes of coopetition as its polarized interferences, beneficial or hurtful, have been made. Coopetition would generate joint value creation, individual firm value creation, or value destruction for both parties [13]. A firm can have more or lesser value than its partners, or costs from coopetitive relationships are much higher than benefits.

Also, research context for coopetition studies should be mentioned. A triadic relationship among a buyer and two suppliers was examined for coopetition in the context of supply chain network [24, 32]. In the small and medium sized enterprise context, coopetition was examined. Small craft beer firms compete with each other while cooperating together against mass producers [20]. Similar to the present study, coopetition between complementors and a platform owner was examined in the context of platform-based market [34].

Based upon the paradox theory, tensions are inevitably generated when contradictory concepts meet with each other, and positive/negative consequences of the tension are contingent on context and a firm's management [2]. Complementors in the platform ecosystem cannot be exceptional, and need to properly manage it. To mitigate negative tensions for complementors, this study presents two important capacities: coopetition balance and coopetition capability.

\section{What is coopetition balance?}

The literature defines coopetition balance as "evenness between competition and cooperation" [13, p. 2522]. The concept can be thought of as the parity between the two paradoxical coexistence. It is the status when a firm finds a harmony between the conflicting forces while pursuing the two seemingly differing goals simultaneously. The main purpose of the contradictory pursuit lies in concurrently accomplishing goals that cooperate to create value together beyond a firm's capacity by leveraging resources from alliance partners and that compete to capture more shares of a joint value created with better quality and performance $[4,15]$. In other words, cooperation and competition for complementors in the platform ecosystem are in need of being reasonably balanced in their collaboration. Without adequate cooperation, there is no existence of alliance, and without sufficient attention to competition, alliances would unwittingly lose their competitive advantage.

In the context of the platform ecosystem, part of interorganizational relationships, there is a tendency to view that value creation is related to cooperation and value appropriation is associated with competition [15]. The bottom line of the argument lies in the understanding that cooperation and competition have inherent trade-offs. This view, however, is not always the case, as literature presents the "natural and persistent" view. Competition in the complementorplatform relationship can help complementors develop their potential, enhance operational excellence, and generate more innovations, all of which are related to value creation to the firm and customers.

Certainly, the interplay of cooperation and competition would either create or destroy values, and thus the academic community attempts to find boundary conditions resulting in good outcomes. While avoiding the risk of undermining cooperation due to competition, the issue of striking an appropriate balance is essential. The tension management through coopetition balance is an imperative task to achieve desired outcomes.

\section{What is coopetition capability?}

Despite possibly beneficial effects of coopetition, the paradoxical coexistence of cooperation and competition would generate potentials to deteriorate 
trust between partners and even break partnership. In line with coping with negative tensions of coopetition, the literature has also presented coopetition capability that could defend competition threats or dampen undesirable impacts of coopetition. Coopetition capability is an organization's capability that manages interorganizational relationships in order to properly confront contradicting realities, and it is defined as "the ability to think paradoxically and to initiate processes that help firms attain and maintain a moderate level of tension, irrespective of the strength of the paradox" [1, p. 19]. It is also described as "evaluative capabilities" [32] in which firms assess situations, make sense of their strategic pursuit, and position properly for better firm performance. Especially, coopetition capability can be a crucial capacity that complementors should possess in case they face competition with a platform owner as part of reducing competitive tensions and producing effective strategic positioning. The capability is not static but dynamic, given that complementors need to continually assess the scope of their cooperation and competition according to changing relationships.

Researchers have acknowledged "swimming with sharks" that large firms are strongly motivated to misappropriate value created through engaging with small firms [14]. It is also consistent with literature on coopetition that firms would be willing to cooperate for value creation but turn their positions to be competitors when it comes to value capture [4, 34]. Not surprisingly, smaller firms see to cooperate with a platform owner with the anticipation of potential benefits, but they are apparently exposed to risks such as misappropriation. To safeguard this challenge, complementors should have coopetition capability that effectively manage tensions between cooperation and competition.

\section{Hypothesis development}

The literature has elaborated on performance outcomes in the context of interorganizational relationships: opportunism, overall satisfaction, relationship performance, and market performance [6] In particular, we have focused on relationship performance as this study examines how coopetition balance and coopetition capability have an impact on their relationships with a platform owner. Relationship performance is described as economic outcomes of a complementor-platform owner partnership in the form of profitability, sales volume, market share, marketing support, and efficiency enhancement [19]. It is about shared outcomes of involving parities as results of coopetitive interactions. As relationship performance refers to the tangible consequences of business relationship between partners, the use of the construct will help the academic community understand the influence of coopetition balance, coopetition capability, and their joint interaction in the context of the platform ecosystem.

It is reported that coopetition can be a productive strategy when a firm establishes a reasonable balance between competing perspectives [13]. This present study acknowledges existing understandings and further examines the impact particularly in the relationship between coopetition balance and relationship performance. Coopetition balance mitigates the adverse effects of the imbalance between cooperation and competition. In case complementors face situations where competition suffocates cooperation, the competitive atmosphere is so intense that complementors hardly trust a platform owner and opportunistic behaviors get spread quickly. Such opposing environments hinder complementors or a platform owner from sharing resources and producing synergies by complementing each entity's limitations. On the other hand, complementors or a platform owner may be complacent in case cooperation trumps over competition. They may have a tendency to do what is required or demanded instead of developing innovations for changing business environments. Without having the leeway to exchange adequate and reciprocal feedback with each other, the relationship would put a conformance to the standards and race to the bottom cost. This type of collaborative pressure can be stressful, particularly when a platform owner puts self-interest first and takes advantage of complementors. When cooperation and competition are balanced on the side of complementors, however, such adverse effects can be controlled and lead coopetition into products results. When complementors reach a dynamic equilibrium between cooperation and competition, comparable emphasis on each element is place for their strategy, and it keeps opposing in check. It may be understood that cooperation and competition have inherent trade-offs. This is in line with the dilemma view of tensions. On the contrary to this view, the paradox theory presents the "natural and persistent" view, indicating that firms continue to respond to paradoxical situations instead of one-time solutions [22]. In other words, rivalrous spirit and mutual cooperation should take place at the same time, and complementors may target common goals and share resources while putting their best efforts to attain excellence over the other. Consequently, the harmony between cooperation and competition enables complementors to drive positive results together, and we present a hypothesis:

H1: Complementors' coopetition balance is positively related to relationship performance in the context of the platform ecosystem. 
Coopetition capability is likely to have a direct impact on relationship performance as it offers an institutional framework that monitors ongoing interactions between a platform owner and the complementor. In other words, coopetition capability is associated with complementors' capacity to properly manage tensions arising from the paradoxical coexistence of cooperation and competition and helps formulate adaptability to fast-changing circumstances more effectively. The paradox theory argues that the "natural and persist view" of tensions is related to opportunities for learning and adaptability. Complementors are willing to work together with a platform owner that provides significant resources. In the course of doing so, there is a chance that complementors may settle down with relational inertia being more content with the status quo and being less efficient and innovative. Relational inertia drives firms to be complacent with what they have and to be less proactive in their own advances on novel and new approaches [13]. In case a platform owner strategically decides to enter the place space of a complementor, its coopetition capability will defend competition threats and dampen negative influences instead of facing challenges with no preparation. Research shows that the market entrance of a platform owner may hurt complementors in a short run, but it will strengthen the platform ecosystem with more benefits in the long run [15]. In particular, volatile changes in relationships, a complementor's capability understanding cooperation and competition will furnish principles, procedures, and proactiveness by alleviating opportunism and elevating relationship performance. As coopetition capability provides complementors with solving problems quickly and accomplishing performance targets, we present the following hypothesis:

\section{H2: Complementors' coopetition capability is positively related to relationship performance in the context of the platform ecosystem.}

An interesting research question is whether the joint use of coopetition balance and coopetition capability is more effective in fostering relationship performance then individual use. It is a common strategy that complementors pursue decreasing costs by utilizing a platform's resources and increasing growth by having more access to a platform's customer base. In doing so, complementors face inevitable challenges that a platform may enter into their product space and increase variances in returns. Just as complementors' dependence on a platform's infrastructure, business processes, and customer interactions, so complementors' smartness should grow by being dynamically equipped with coopetition balance and coopetition capability. We argue that synergetic effects could exist for relationship performance when both coopetition balance and coopetition capability are simultaneously in place. Coopetition balance provides firms with stability by "offsetting potential challenges and keeping opposing forces in check" [13, p. 2522]. In other words, the balance approaches of cooperation and competition bring firms well-adjusted responses to two conflicting elements and enhance a firm's flexibility. Coopetition capability provides complementors with an institutional framework that monitors interactions between the platform owner and the firm. A combination of coopetition balance and coopetition capability can pay continued attention to relationship changes between the platform and complements and unlock their potentials to grow continually. It is associated with complementors' capacity to continue to assess the current situation and develop their responses instead of one-time solution based upon the paradox theory. The combination of coopetition balance and coopetition capability can offer the firm's configuration that understand market changes and reconfigurations that reorganize their resources and respond to the market. The two forces offer stimulation for executing proper strategies. We propose that these together will lead to better relationship performance.

H3: The impact of coopetition balance on relationship performance is moderated by coopetition capability, such that the relationship becomes stronger in the presence of high coopetition capability in the context of the platform ecosystem.

\section{Research methods}

This study selected the platform ecosystem at Amazon.com for several reasons. Amazon is a leading online e-commerce platform in the world, and Amazon marketplace launched in 2000 by enabling third-party sellers to introduce their products to Amazon customers. FBA (Fulfillment by Amazon) allows complementors to use Amazon's infrastructure for inventory control, storage, and shipping with pick-and-pack customer service. Also, research has shown that Amazon enters complementors' market for reorganizing their product quality and profit-maximizing strategies [34]. Although a different platform would be a good candidate, Amazon.com is arguably the most appropriate setting to investigate the impact of coopetition.

The survey questionnaire was created and administered to senior-level management. Although this research hired a professional data collection company for recruiting Amazon vendors, the survey administration and data collection processes were under 
the control of the authors. The use of a data collection company increased our ability to cover the intended population of this study and then enhanced the generalizability of the research results.

Prior to conducting a large-scale survey, we conducted a pilot study with two ways: four academic researchers who have sufficient knowledge and experiences in IS, operations, and management and 64 vendors that do their businesses with Amazon. Following a check on convergent and discriminant validity, necessary changes were made. A large-scale survey was administered to test the research model. A total of 625 Amazon vendors who were qualified for the survey were invited to answer the survey, and 365 firms completed it, resulting in a $58.4 \%$ response rate. Respondents held job titles such as C-level executives, vice presidents, directors, or senior managers. Table 1 presents the demographic features of the samples in this study. Response/non-response bias was examined by comparing the earlier responses with the later ones. A Chi-square test on annual sales and number of employees showed no significant difference.

\section{Table 1. Demographic features of the sample}

\begin{tabular}{|l|r|}
\hline Category & Percent \\
\hline Home \& Kitchen & $10.4 \%$ \\
\hline Health \& Personal Care & $10.4 \%$ \\
\hline Clothing \& Accessories & $13.4 \%$ \\
\hline Books \& Movies & $6.3 \%$ \\
\hline Toys \& Games & $6.8 \%$ \\
\hline Sports \& Outdoors & $4.4 \%$ \\
\hline Beauty & $6.3 \%$ \\
\hline Grocery \& Gourmet Food & $6.0 \%$ \\
\hline Tools \& Home Improvement & $2.7 \%$ \\
\hline Pet Supplies & $3.0 \%$ \\
\hline Office Products & $6.3 \%$ \\
\hline Patio, Lawn \& Garden & $0.5 \%$ \\
\hline Automotive & $1.4 \%$ \\
\hline Arts, Crafts \& Sewing & $4.1 \%$ \\
\hline Baby Products & $1.6 \%$ \\
\hline Jewelry & $3.0 \%$ \\
\hline Cell Phones \& Accessories & $5.8 \%$ \\
\hline Other & $7.4 \%$ \\
\hline Annual Sales & \\
\hline Less than $\$ 100,000$ & $25.8 \%$ \\
\hline$\$ 100,000-\$ 500,000$ & $21.9 \%$ \\
\hline$\$ 500,000-\$ 1$ million & $18.1 \%$ \\
\hline$\$ 1$ million - \$5 million & $18.1 \%$ \\
\hline Over $\$ 5$ million & $16.2 \%$ \\
\hline Number of Employees & \\
\hline $1-5$ & $18.9 \%$ \\
\hline $6-10$ & $7.4 \%$ \\
\hline $11-50$ & $12.9 \%$ \\
\hline
\end{tabular}

\begin{tabular}{|l|r|}
\hline $51-100$ & $13.2 \%$ \\
\hline $101-500$ & $20.3 \%$ \\
\hline $501-1,000$ & $19.2 \%$ \\
\hline Over 1000 & $8.2 \%$ \\
\hline
\end{tabular}

\subsection{Measures}

We adapted existing items for cooperation $[5,9,33]$, coopetition capability [1], and relationship performance $[6,19]$. Our survey employed multiple-item measures for all of the construct. In particular, we used latent congruence modeling to develop coopetition balance from separate items of cooperation and competition. Latent congruence modeling is a variation of structural equation modeling that was recently advocated as a useful tool to measure congruence between two competing constructs $[12,23]$. The modeling is especially relevant in the context of coopetition that emphasizes fit between two conflicting concepts in the platform ecosystem. Latent congruent modeling controls for measurement errors, examines measurement equivalence, and provides a more relevant measure of congruence. It creates two second-order factors from two components of interest: mean (i.e., level) and differences (i.e., congruence) based upon the formula below.

$$
\begin{aligned}
& \text { Level }=\mid \text { Cooperation }+ \text { Competition } \mid / 2 \\
& \text { Congruence }=\mid \text { Cooperation-Competition } \mid
\end{aligned}
$$

In the context of this study, the level implies the average of cooperation and competition, and the congruence represents similarity in the extent of cooperation and competition. Coopetition balance is proxied by congruence [23]. A higher congruence score indicates a greater difference between cooperation and competition. It means dissimilarity rather than similarity and overemphasizes one of the two activities instead of pursuing both. As greater coopetition illustrates a smaller difference between cooperation and competition, we multiplied congruence scores by -1 to help interpretations.

This study included five control variables: (1) relationship length with Amazon, (2) extent of using FBA, (3) percent of sales with Amazon, (4) overall sales, and (5) number of employees. These variables are chosen to control for complementors' dependence on Amazon and their size. Controlling for these variables will better examine the impact of coopetition balance and coopetition capability on relationship performance.

To decrease the common method bias, we followed the guideline proposed by Podsakoff et al. [25]. A Harman's one-factor test was employed for common 
method bias. Results show five factors accounting for 80.39 percent of total variance (eigenvalue $>1$ ) and the first factor accounted for 15.64 percent of the variance. The test suggests that common method bias is not a concern.

\subsection{Measurement properties and hypothesis testing}

This study conducted analyses in two main steps: (1) factor analysis through structural equation modeling and (2) hypothesis testing through regression analysis. Confirmatory factor analysis was implemented with Amos to assess measurement properties in our dataset. The measurement model using Amos showed a good fit (Chi-Square/d.f. $=2.737, \mathrm{NFI}=.932, \mathrm{CFI}=.955, \mathrm{IFI}=$ .955 , RFI = .920). The RMSEA value is .061 with $90 \%$ confidence level stretching from .055 to .068 . All factor loadings were greater than .70 and were highly significant. Values of Cronbach's alpha ranged from .89 and .94, as shown in Table 2. The results showed that convergent validity deemed to be established. AVE in all constructs was greater than .500. Discriminant validity was examined by the square root of AVE for the associate construct which needs to be higher than all other correlations. The data used in this study had no concern with discriminant validity. Table 2 provides a correlation table with Cronbach's alpha, AVE, and composite reliability for this study.

\section{Table 2. Descriptive statistics and inter-} correlations

\begin{tabular}{|l|c|c|c|c|c|c|}
\hline & $\mathrm{CA}^{\mathrm{a}}$ & $\mathrm{CR}^{\mathrm{b}}$ & AVE $^{\mathrm{c}}$ & 1 & 2 & 3 \\
\hline 1 & .89 & .88 & .61 & & & \\
\hline 2 & .92 & .92 & .71 & $.24^{\mathrm{d}}$ & & \\
\hline 3 & .87 & .87 & .64 & .26 & .10 & \\
\hline 4 & .94 & .94 & .76 & .46 & .23 & .14 \\
\hline
\end{tabular}
variances extracted, d Squared correlation; 1:
Cooperation, 2: Competition, 3: Coopetition capability, 4:
Relationship performance

We employed hierarchical ordinary least squares regression to test hypotheses postulated in this study. A three-step procedures were taken to investigate the impact of control variables at stage 1 , of the main effects of coopetition balance and coopetition capability at stage 2, and of the moderating effect of coopetition capability between coopetition balance and relationship performance. Note that variables were mean-centered in order to reduce the potential for multicollinearity [10]. The regression results show that both coopetition balance and coopetition capability are statistically positive related to relationship performance, supporting
$\mathrm{H} 1(\beta=.17, \mathrm{p}<.05)$ and $\mathrm{H} 2(\beta=.61, \mathrm{p}<.01)$, as shown in Table 3. In order to assess the presence of the interaction term, we examined the change in $\mathrm{R}^{2}$ between Model 2 and Model 3 [10]. In addition, a simple slope analysis was conducted to inspect the form of interaction. This test was done by calculating simple sloes between plus and minus one standard deviation from the moderator's mean and evaluated the coefficients at both levels [10]. The results in Figure 1 are based on unstandardized results.

The analysis uncovers two important findings. First, there is a significant moderating effect between coopetition balance and coopetition capability, supporting H3 $(\beta=.38, \mathrm{p}<0.01)$, as shown in Table 3.

\section{Table 3. Summary of regression results}

\begin{tabular}{|l|l|l|l|}
\hline \multicolumn{4}{|c|}{ DV: Relationship Performance } \\
\hline Variables & Model 1 & Model 2 & Model 3 \\
\hline Longevity & 0.03 & 0.02 & 0.04 \\
\hline $\begin{array}{l}\text { Fulfilled by } \\
\text { Amazon }\end{array}$ & 0.04 & 0.01 & 0.04 \\
\hline $\begin{array}{l}\text { \% of Sales with } \\
\text { Amazon }\end{array}$ & 0.11 & 0.03 & 0.01 \\
\hline Sales & $0.18^{* *}$ & 0.03 & 0.02 \\
\hline $\begin{array}{l}\text { Number of } \\
\text { Employees }\end{array}$ & -0.02 & -0.02 & -0.03 \\
\hline $\begin{array}{l}\text { Coopetition } \\
\text { Balance }\end{array}$ & & $0.17^{* *}$ & $0.15^{* * *}$ \\
\hline $\begin{array}{l}\text { Coopetition } \\
\text { Capability }\end{array}$ & & $0.61^{* * *}$ & $0.95^{* * *}$ \\
\hline $\begin{array}{l}\text { Coopetition } \\
\text { Balance X } \\
\text { Coopetition } \\
\text { Capability }\end{array}$ & & $0.38^{* * *}$ \\
\hline & & 0.34 & 0.09 \\
\hline Adjusted $\mathrm{R}^{2}$ & 0.06 & 0.40 & 0.43 \\
\hline$\Delta$ Adjusted $\mathrm{R}^{2}$ & & $106.31^{* * *}$ & $16.09^{* *}$ \\
\hline$\Delta \mathrm{F}$ & $4.78^{* *}$ & & \\
\hline
\end{tabular}

${ }^{\star} p<.10,{ }^{* *} p<.05 ;{ }^{* * *} p<001$; The items reported are standardized regression coefficients. DV: Dependent variable, Variance inflation factor (VIF) were calculated to examine multicollinearity. VIF values are less 2.3, suggesting that multicollinearity is not a concern.

Results also show that it is much more effective when coopetition balance and coopetition capability are launched together. When the level of both coopetition balance and coopetition capability is high, relationship performance exhibits much stronger achievements that a level of both cases (i.e., 6.41 vs. 3.53), as shown in Figure 1. Second, the impact of coopetition balance ameliorates significantly in the present of coopetition capability, demonstrating the vital moderating role of coopetition capability. While complementors with a low 
level of cooperation capability show improvements in relationship performance regardless of levels of coopetition balance, firm equipped with a high level of cooperation capability made a noteworthy leap from 5.25 to 6.41 under low and high coopetition balance, respectively. Taken together, the simple slope analysis presents an evidence of moderating role of coopetition capability.

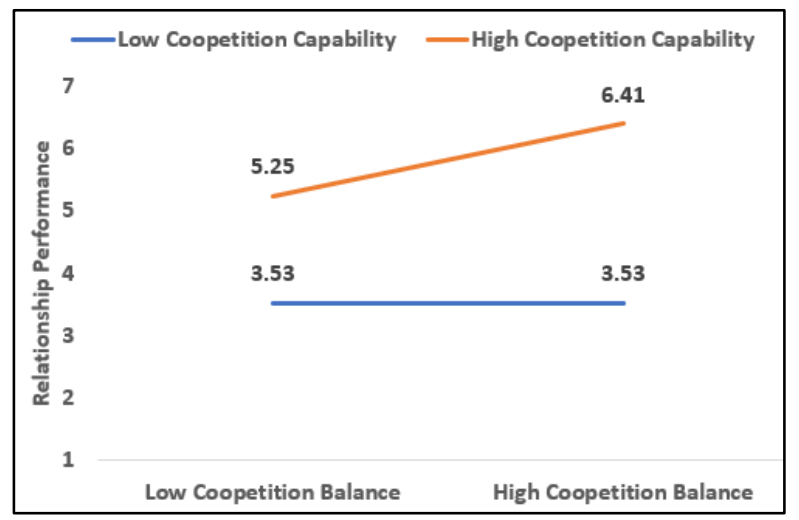

Figure 1. Interaction effect between coopetition capability and coopetition balance

\section{Discussion}

The success of the platform ecosystem relies heavily on the dynamic collaboration of complementors and a platform owner $[21,30]$, but the strategic alliance can be polluted by direct competition due to a platform owner's entry into complementors' product space [34]. As a result, coopetition is established, and tensions are likely to be intensified under the condition of scarcity[22]. Unfortunately, complementors are placed in the position of scarcity such as a lack of customer access and logistical infrastructure. Coopetition can provide a crucial foundation for steady cooperation to complement each entity's goals, while unnecessary stress and defense can hurt their sound relationships. This study helps academicians and practitioners understand how to increase positive responses and reduce negative tensions in the context of coopetition.

\subsection{Implications for research}

The first theoretical contribution of this study is to provide a theory-based research model that reveals how to enhance relationship performance through coopetition balance and coopetition capability. The literature has called for studies on bring together the apparent divide between cooperation and competition to shed light on the reality firms face in the current business environment [15]. As the field of coopetition has been drawn attention from researchers and practitioners, its nature and management have been illuminated [13, 15]. Studies, however, are generally theoretical or anecdotal, and empirical studies are rare. This study makes a contribution to literature by providing a theory-driven, empirically-tested model that nurtures a firm's agility via coopetition and that utilizes resources to have an advantageous position in a coopetitive environment. Additionally, this study has employed latent congruence modeling to develop coopetition as the method incorporates measurement errors and model covariance among individual items under cooperation and competition. This methodological provision as part of finding coopetition balance gives robust insights into the literature. Firms need to harness tensions arising from cooperation and competition, resulting in enhancing positive responses and negative impacts.

The second theoretical contribution of this study to elaborate on coopetition with a contextual focus on a platform-based market. Product/service-based strategies have been losing ground to platform-based strategies. As the network economy has been emphasized as part of value creation, a motto, "Forget Products and Forge Platform," is prevalent in the business field. A platform mediates relationships between consumers and complementors together with feedback reinforcing strategies of complementary products and attracting more users. Studies have centered on platform owners as a focal point of interest: platform owners' pricing decision [8, 27] and interactions between competing platforms [7]. However, studies on concentrating on complementors, producing significant values to a platform, are in need of more attention, and this perspective will give more holistic approaches to understanding a platform ecosystem. Also, research has focused on positive impacts of cooperation between a platform owner and complementors. Studies, on the other hand, emphasizes dark sides of collaboration, often called "swimming with the shark", need receive more attention to investigate how small firms can produce benefits. Platform owners and complementors have established their interfirm relationships with cooperation and engage in competition as part of ecosystems [15]. For example, Intel avoids direct competition with competitors, but enters markets when complements' products are underperforming by signaling innovations through competition [34]. Amazon has begun providing own products to customers directly, leading to competition with complementors. Complementors should be aware of their strategic position with regard to coopetition emphasizing value creation, cooperation, value appropriation or competition. This study provides 
significant values with regard to value cocreation in the perspective of complementors.

The third contribution of the study is to provide two coequal capacities (i.e., coopetition balance and coopetition capability) and their individual and interaction effects on relationship performance. The literature has acknowledged positive and negative effects of coopetition [2, 13], and the mixed results are requested to be reconciled. In other words, coopetition can damage value for both parties on the contrary to their expectations, and its negative impact should be much worse on complementors than on a platform owner due to its size and resources. As firms should go through three steps of accepting, accommodating, and differentiating/integrating [28] with regard to coopetitive strategies, complementors should be aware that coopetition is ongoing responses rather than onetime resolution. That is, coopetition balance and coopetition capability are dynamic flexibility that complementors need to possess for their adaptive capacity. In the platform ecosystem, establishing cooperative relationships between complementors and a platform owner via proper communication and respect are crucial to creating path-breaking products [21]. Competition seems to be detrimental to the relationship in the platform ecosystem, the literature presents that it will reinforce their capacities over time [15]. Not only does coopetition balance helps sustain the stability of two forces but also it motivates firms to stay alert and continue for better performance. More critically, coopetition balance deters complementors to fall into complacency or stay the status quo. Complementors should manage ostensibly incompatible goals of cooperation and competition. While cooperating, complementors should strengthen their competitive advantage. With the complexity of the market landscape, taking an approach with coopetition capability open up more opportunities.

\subsection{Implications for practice}

This study has implications for managers who face competition in the platform ecosystem. Complementors may have engaged with a platform owner with the expectation of cooperation. As their products/services show potentials for growth, a platform owner may entertain a second thought and even decides to directly compete with complementors. This study finds a positive and significant impact of coopetition balance on relationship performance. It indicates that complementors should not merely focus on cooperation with a platform owner, but should prepare themselves for the competitive circumstances. As competitive pressures from a platform owner stream into relationships and gradually erode the customer base, complementors should also increase competitive approaches toward a platform owner and find a balanced way.

The present study finds the presence of joint effects of coopetition balance and coopetition capability. The results of the study suggest that complementors pursue both coopetition balance and coopetition capability jointly in dealing with coopetition. Coopetition balance has a significant impact on relationship performance significantly, but there is also a moderating impact of coopetition capability on relationship performance. Regression coefficients indicate that moderating effects of coopetition capability between coopetition balance and relationship performance is higher than that of the individual effect of coopetition balance on relationship performance. Pursuing evenness of cooperation and competition is critical for sustaining competitive advantage. When the balance is combined with a firm's capacity to manage paradoxical coexistence through coopetition capability, their adaptive capacity will be intensified.

It is noteworthy to mention that coopetition capability is more influential than coopetition balance and interactions between coopetition balance and coopetition capability. While coopetition balance focuses on the evenness of cooperation and competition, coopetition capability is the ability to respond to the coopetition by seeking alternative strategies and to continuously adjust their relationship with the platform owner. It is also called evaluative capability that assesses situations, makes sense of realities, and responds to changes effectively. From the outset of the partnership, complementors should not only focus on the compliance with the platform owner but also develop an organizational capability to manage tensions and prepare themselves for changing markets.

\section{Conclusion}

This study contributes to the literature by adding values with conceptually theorizing and empirically testing coopetition capability and coopetition balance as important leverages that firms can cope with the environmental change. We extend prior research mainly conceptually examined. Delving into the concept of coopetition, more sophistically, our theory considers the impact of coopetition capability and balance as the positive consequences. In the face of such tensions from coopetition, balance and capability can fuel complementors' adaptive capacity in the platform ecosystem.

\section{References}


[1] Bengtsson, M., T. Raza-Ullah, and V. Vanyushyn, "The coopetition paradox and tension: The moderating role of coopetition capability", Industrial Marketing Management 53, 2016, pp. 19-30.

[2] Bouncken, R.B., V. Fredrich, P. Ritala, and S. Kraus, "Coopetition in new product development alliances: advantages and tensions for incremental and radical innovation", British Journal of Management 29(3), 2018, pp. 391-410.

[3] Bouncken, R.B., J. Gast, S. Kraus, and M. Bogers, "Coopetition: a systematic review, synthesis, and future research directions", Review of Managerial Science 9(3), 2015, pp. 577-601.

[4] Brandenburger, A., and B.J. Nalebuff, Co-opetition, Harvard Press, Boston, MA, 1996.

[5] Cannon, J.P., and W.D. Perreault, "Buyer-seller relationships in business markets", Journal of marketing research, 1999, pp. 439-460.

[6] Cao, Z., and F. Lumineau, "Revisiting the interplay between contractual and relational governance: A qualitative and meta-analytic investigation", Journal of Operations Management 33, 2015, pp. 15-42.

[7] Casadesus-Masanell, R., and G. Llanes, "Mixed source", Management Science 57(7), 2011, pp. 1212-1230.

[8] Chen, J., M. Fan, and M. Li, "Advertising Versus Brokerage Model for Online Trading Platforms.”, MIS Quarterly 40(3), 2016, pp. 575-596.

[9] Cheung, M.-S., M.B. Myers, and J.T. Mentzer, "Does relationship learning lead to relationship value? A crossnational supply chain investigation", Journal of operations management 28(6), 2010, pp. 472-487.

[10] Cohen, J., P. Cohen, S.G. West, and L.S. Aiken, Applied multiple regression/correlation analysis for the behavioral sciences, Lawrence Erlbaum, Mahwah, NJ, 2003.

[11] Constantinides, P., O. Henfridsson, and G.G. Parker, "Introduction-Platforms and infrastructures in the digital age", 29(2), 2018, pp. 381-400.

[12] Fernhaber, S.A., and P.C. Patel, "How do young firms manage product portfolio complexity? The role of absorptive capacity and ambidexterity", Strategic Management Journal 33(13), 2012, pp. 1516-1539.

[13] Gnyawali, D.R., and T.R. Charleton, "Nuances in the Interplay of Competition and Cooperation: Towards a Theory of Coopetition", Journal of Management 44(7), 2018, pp. 2511-2534.

[14] Hallen, B.L., R. Katila, and J.D. Rosenberger, "How do social defenses work? A resource-dependence lens on technology ventures, venture capital investors, and corporate relationships", Academy of Management Journal 57(4), 2014, pp. 1078-1101.

[15] Hoffmann, W., D. Lavie, J.J. Reuer, and A. Shipilov, "The interplay of competition and cooperation", Strategic Management Journal 39(12), 2018, pp. 3033-3052.

[16] Leslie, J., P. Li, and S. Zhao, "Managing Paradox: Blending East and West Philosophies to Unlock Its Advantages and Opportunities", 2015.

[17] Lewis, M.W., "Exploring paradox: Toward a more comprehensive guide", Academy of Management review 25(4), 2000, pp. 760-776.

[18] Li, H., Y. Fang, K.H. Lim, and Y. Wang, "PlatformBased Function Repertoire, Reputation, and Sales
Performance of E-Marketplace Sellers", MIS Quarterly 43(1), 2019, pp. 207-236.

[19] Liu, Y., Y. Luo, and T. Liu, "Governing buyer-supplier relationships through transactional and relational mechanisms: Evidence from China", Journal of Operations Management 27(4), 2009, pp. 294-309.

[20] Mathias, B.D., A. Huyghe, C.J. Frid, and T. Galloway, "An Identity Perspective on Coopetition in the Craft Beer Industry”, Strategic Management Journal 39(12), 2017, pp. $1-30$.

[21] McIntyre, D.P., and A. Srinivasan, "Networks, platforms, and strategy: Emerging views and next steps", Strategic Management Journal 38(1), 2017, pp. 141-160. [22] Miron-Spektor, E., A. Ingram, J. Keller, W.K. Smith, and M.W. Lewis, "Microfoundations of organizational paradox: The problem is how we think about the problem", Academy of Management Journal 61(1), 2018, pp. 26-45. [23] Patel, P.C., J.G. Messersmith, and D.P. Lepak, "Walking the tightrope: An assessment of the relationship between high-performance work systems and organizational ambidexterity", Academy of Management Journal 56(5), 2013, pp. 1420-1442.

[24] Pathak, S.D., Z. Wu, and D. Johnston, "Toward a structural view of co-opetition in supply networks", Journal of Operations Management 32(5), 2014, pp. 254-267.

[25] Podsakoff, P.M., S.B. MacKenzie, Jeong-Yeon Lee, and N.P. Podsakoff, "Common Method Biases in Behavioral Research: A Critical Review of the Literature and Recommended Remedies", Journal of Applied Psychology 88(5), 2003, pp. 879-903.

[26] Ritala, P., and L.-M. Sainio, "Coopetition for radical innovation: technology, market and business-model perspectives", Technology Analysis \& Strategic Management 26(2), 2014, pp. 155-169.

[27] Seamans, R., and F. Zhu, "Responses to entry in multisided markets: The impact of Craigslist on local newspapers", Management Science 60(2), 2013, pp. 476493.

[28] Smith, W.K., "Dynamic decision making: A model of senior leaders managing strategic paradoxes", Academy of Management Journal 57(6), 2014, pp. 1592-1623.

[29] Smith, W.K., and M.W. Lewis, "Toward a theory of paradox: A dynamic equilibrium model of organizing", Academy of management Review 36(2), 2011, pp. 381-403.

[30] Song, P., L. Xue, A. Rai, and C. Zhang, "The ecosystem of software platform: A study of asymmetric cross-side network effects and platform governance", MIS Quarterly 42(1), 2018, pp. 121-142.

[31] Tiwana, A., "Evolutionary competition in platform ecosystems", Information Systems Research 26(2), 2015, pp. 266-281.

[32] Wilhelm, M., and J. Sydow, "Managing Coopetition in Supplier Networks-A Paradox Perspective", Journal of Supply Chain Management 54(3), 2018, pp. 22-41. [33] Yang, Z., C. Su, and K.-S. Fam, "Dealing with institutional distances in international marketing channels: Governance strategies that engender legitimacy and efficiency", Journal of Marketing 76(3), 2012, pp. 41-55. [34] Zhu, F., and Q. Liu, "Competing with complementors: An empirical look at Amazon. com”, Strategic Management Journal 39(10), 2018, pp. 2618-2642. 